\title{
The Bonn University lidar at the Esrange: technical description and capabilities for atmospheric research
}

\author{
U. Blum ${ }^{1, *}$ and K. H. Fricke ${ }^{1}$ \\ ${ }^{1}$ Physikalisches Institut der Universität Bonn, Nussallee 12, 53115 Bonn, Germany \\ *now at: Forsvarets forskningsinstitutt, Postboks 25, N-2027 Kjeller, Norway
}

Received: 11 October 2004 - Revised: 23 March 2005 - Accepted: 3 May 2005 - Published: 28 July 2005

\begin{abstract}
The Bonn University operates a Rayleigh/Mie/Raman backscatter lidar at the Esrange near the Swedish city of Kiruna, north of the Arctic circle. The lidar system covers the atmosphere from about $4 \mathrm{~km}$ to $100 \mathrm{~km}$ altitude and it is capable of measuring aerosols in the tropo-, strato-, and mesosphere, as well as of determining temperature profiles in the aerosol-free part of the atmosphere (i.e. above $30-\mathrm{km}$ altitude). Density tuned fixed-spacer etalons provide daylight capability and thus increased sensitivity to noctilucent clouds during polar summer. Polarisation measurements allow liquid and solid phase discrimination for aerosol and cloud particles in the tropo- and stratosphere. The derived temperature profiles can be used for the detection and analysis of atmospheric gravity waves. Although several lidar experiments are situated in polar latitudes, a comprehensive instrument which covers the troposphere, stratosphere, and mesosphere, is daylight capable, and observes temperature profiles, as well as aerosols, is exceptional. In this article a technical description, in particular, of the optical configuration of this experiment is given, as well as an overview of achievable geophysical parameters. The potential for geophysical analyses is shown.
\end{abstract}

Keywords. Atmospheric composition and structure (Instruments and techniques; Aerosols and particles; Pressure, density and temperature) - Meteorology and atmospheric dynamics (Middle atmosphere dynamics)

\section{Introduction}

The polar middle atmosphere has been subject of intense research for several decades. Extreme atmospheric states occur in winter as well as in summer, leading to the formation of polar stratospheric clouds (PSCs; Størmer, 1929) and noctilucent clouds (NLCs; Jesse, 1885), respectively, in the dry middle atmosphere. PSCs play a major role in

Correspondence to: U. Blum

(ubl@ffi.no) polar ozone depletion (Crutzen and Arnold, 1986; Solomon, 1999), and NLCs are discussed as an indicator of global change (Thomas, 1996; von Zahn, 2003). The formation of these clouds is closely connected to the dynamics of the polar atmosphere. Whereas polar stratospheric clouds regularly occur in temperature minima caused by stationary gravity waves (Dörnbrack et al., 2002), the cooling of the mesopause in summer is attributed to a momentum flux induced change of the global circulation (Fritts and Alexander, 2003).

Numerous methods and instruments are used to observe these clouds, as well as the thermal and dynamical state of the atmosphere: these are for example, in-situ measurements, as well as active and passive remote sensing from the ground and from space. Ground-based lidars represent one well established method for this purpose. Lidar systems allow one to continuously follow the changing state of the atmosphere with high vertical and temporal resolution, as long as the weather conditions permit operations. In fact, lidars cover an altitude range exceeding that of an individual balloon flight or rocket-borne instrument. Moreover lidars have a better vertical resolution than passive satellite remote sensing instruments.

Middleton and Spilhaus (1953) introduced the name "Lidar" first to the literature, using pulsed flashlamps and timeresolved detectors. Shortly after the first successful operation of a laser (Maimann, 1960), lasers were used as a new light source for lidars (Fiocco and Grams, 1964; Collis and Ligda, 1964). Lidars for different objectives were constructed very soon and much improved since that time. For example:

- Aerosol in the troposphere (Kent et al., 1967; Sassen and Benson, 2001), in the stratosphere (McCormick et al., 1982; Flueglistaler et al., 2002), and in the mesosphere (Hansen et al., 1989; Fiedler et al., 2003).

- Temperatures in the mesopause region by resonance scattering (Fricke and von Zahn, 1984; She et al., 2002), in the middle stratosphere and mesosphere by Rayleigh scattering (Kent and Wright, 1970; Chen et al., 2004), and in the troposphere and lower stratosphere 
by rotational Raman scattering (Arshinov et al., 1983; Behrendt and Reichardt, 2000). These different methods can also be used simultaneously to retrieve a continuous temperature profile from the ground to the mesopause (Alpers et al., 2004).

- Detection of different atmospheric constituents such as ozone (Pelon and Mégie, 1982; Hansen et al., 2003) or water vapor (Melfi and Lawrence, 1969; Kao et al., 2001).

The acronym lidar stands for $L i g h t$ Detecting $a$ nd Ranging. Each lidar comprises a light source with an accompanying transmitter branch, as well as a receiving and analysing system. Depending on the scattering mechanism which is exploited, lidars are named differently. The Bonn University lidar utilises the backscattered light determined by Rayleigh-, Mie- and Raman-scattering and is thus called a Rayleigh/Mie/Raman backscatter lidar, or RMR lidar for brevity.

First in this article we deduce the requirements for the lidar instrument from the scientific objectives and the geographical location. Next the light source and the transmitter are described in Sect. 3, and in Sect. 4 the receiving system is explained. The capabilities of the lidar and how the instrument meets the requirements are shown in Sect. 5.

\section{Requirements for the lidar}

The main scientific objectives for this lidar are found in the stratosphere and mesosphere. However, to obtain a comprehensive picture of the atmosphere a coverage of the whole atmosphere from the ground up to the mesopause is desirable, i.e. the troposphere needs to be included. The U. Bonn lidar covers the range from about $4 \mathrm{~km}$ up to $100 \mathrm{~km}$ altitude. In this altitude range the atmospheric density decreases by about 6 orders of magnitude. Due to the observation geometry the backscattered signal in the field of view of the instrument decreases like $1 / \mathrm{r}^{2}$, where $\mathrm{r}$ is the range to the scattering altitude. This amounts to a factor of 600 in the lidar altitude range. The entire signal thus decreases by about 7-8 orders of magnitude which imposes a minimum dynamic range that the photomultipliers and counting electronics must be capable of dealing with. The observations should comprise aerosol monitoring throughout the whole atmosphere, which includes optically thin $(\tau<1)$ tropospheric and cirrus clouds, polar stratospheric clouds during winter, and noctilucent clouds during summer. Of further interest are the stratospheric background aerosol (Junge-layer), stratospheric aerosols of volcanic origin, and soot from wildfire.

For PSCs a classification of the observed cloud particles is desirable because the efficiency of PSCs for chlorine activation depends on the cloud type. Different types of PSCs are well established (McCormick et al., 1978; Pool and McCormick, 1988) and several classification schemes based on scattering properties are described (e.g. by Browell et al.,
1990; Toon et al., 2000; Biele et al., 2001). For such a classification a determination of the depolarisation of the backscattered light is essential. If the aerosols cause changes in the polarisation of the backscattered light with respect to the incoming light, the shape of the aerosols cannot be spherical and thus the phase must be solid. Furthermore, the surface area density of the PSC particles is important for atmospheric chemistry, thus an estimate of the particle size distribution is desired. An estimate of the particle size can be obtained from measurements at three or more different wavelengths (e.g. Beyerle et al., 1994). In the case of large particles (radius $\gg \lambda_{\text {Lidar }}$ ) the aerosol extinction is proportional to the aerosol surface area density and thus can be estimated from the transmission of the aerosol layer on only one wavelength.

From 1990-1995 a predecessor of the present lidar was situated at the Andøya Rocket Range in northern Norway. It was later moved to the Esrange $(67.88 / 21.06 \mathrm{E})$ near the Swedish city of Kiruna, about $150 \mathrm{~km}$ north of the Arctic circle and since 1997 has been operated there. This geographic location means light nearly all day long during summer, which is the season of noctilucent clouds. Thus, for NLC observations the lidar has to be fully daylight capable, which can only be achieved by very narrow optical filter systems, such as Fabry-Perot etalons. It also requires a small spectral bandwidth of the light source, i.e. the laser. A small divergence of the laser beam allows a smaller field of view for the receiving system which results in a smaller contribution from the solar background. To avoid the loss of signal from the transmission of the etalons during nighttime measurements, a rapid change-over between the daytime and nighttime configuration of the detection branch is desired.

About $100 \mathrm{~km}$ west and north of the Esrange the Scandinavian mountain ridge is a major source for orographically induced gravity waves (Volkert and Intes, 1992; Blum et al., 2004). Gravity waves are easily detected in atmospheric temperature profiles. Thus the lidar must be capable of measuring temperature profiles in the middle atmosphere. Temperature profiles are calculated from low-noise molecular number density profiles using the barometric equation. The scientific objectives and associated technical requirements are summarised in Table 1.

\section{Transmitter}

The requirements listed above must be met in part by the transmitter branch. These are the requirements for the different wavelengths, the purity of the polarisation of the emitted light, and the narrow bandwidth, as well as the small divergence, which are essential conditions for daylight measurements.

The transmitter branch of the lidar consists of a laser light source and following optics. The laser is a pulsed solidstate Nd:YAG laser (Continuum YG682-20) with a repetition rate of $20 \mathrm{~Hz}$, which can emit up to three wavelengths at $1064 \mathrm{~nm}, 532 \mathrm{~nm}$, and $355 \mathrm{~nm}$. A single-mode continuous 
Table 1. Scientific objectives and necessary technical requirements on the U. Bonn lidar at the Esrange.

\begin{tabular}{ll}
\hline Scientific objective & Technical requirement \\
\hline covering troposphere, stratosphere and mesosphere & detection devices covering 7-8 orders of magnitude \\
classification of PSCs & detection of different polarisations \\
estimation of PSC particle size and shape & at least three wavelengths \\
detection of background aerosol & long wavelength for increased sensitivity to small aerosols \\
NLC observation & daylight capability \\
& $\rightarrow$ narrow band optical filters \\
temperature calculation & $\rightarrow$ small laser beam divergence \\
\hline
\end{tabular}

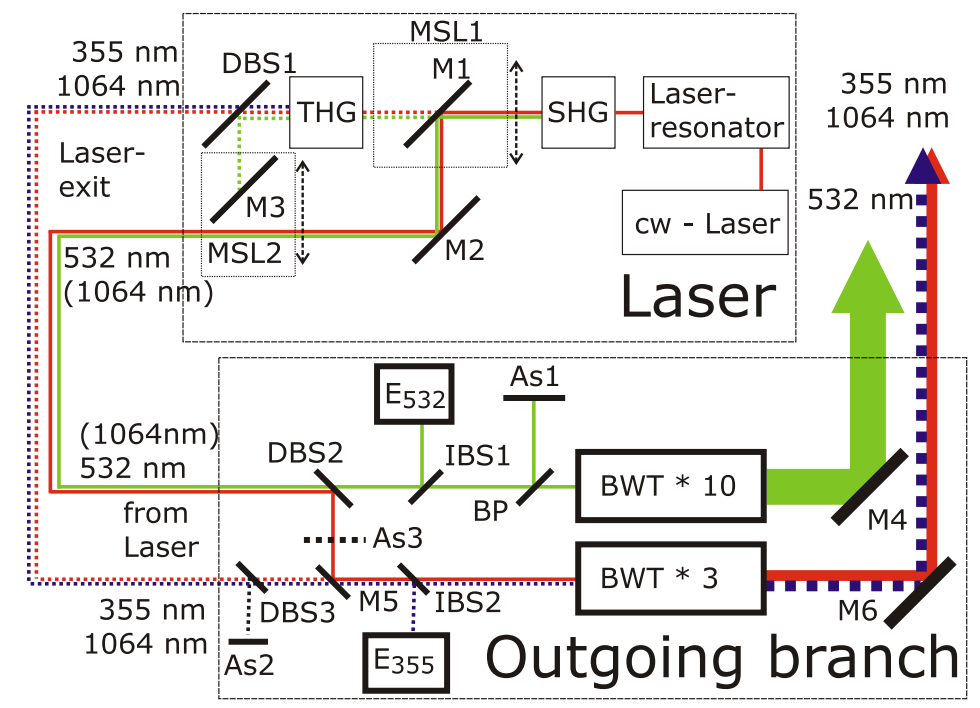

Fig. 1. Optical setup of the transmitter branch in $2-\lambda$ mode (solid lines) and $3-\lambda$ mode (dashed lines). See text for details.

wave seeder laser injects light at $1064 \mathrm{~nm}$ wavelength in the laser-resonator of the power laser and reduces the bandwidth from $120 \mathrm{GHz}(\approx 450 \mathrm{pm}$ at $1064 \mathrm{~nm}$ wavelength) to $250 \mathrm{MHz}$ ( $\approx 0.9 \mathrm{pm}$ at $1064 \mathrm{~nm}$ wavelength). This bandwidth reduction is one of the requirements for daylight operations; at the operational daylight wavelength $532 \mathrm{~nm}$ the doubling process reduces the bandwidth even further. The given setup allows one to operate the laser in two different modes: (1) a two color mode, using infrared light at $1064 \mathrm{~nm}$ and green light at $532 \mathrm{~nm}$ and (2) a three color mode, transmitting on all three wavelengths.

The optical setup of the transmitter branch is shown in Fig. 1. The principal wavelength of the laser is in the infrared at $1064 \mathrm{~nm}$ which is doubled to $532 \mathrm{~nm}$ (green light) by a second harmonic generator (SHG). Optionally, a third harmonic generater (THG) can be used to produce ultraviolet light at $355 \mathrm{~nm}$ wavelength. In case of the $2-\lambda$ mode the mirrors M1 and M2 direct the beam out of the laser housing. External to the laser housing a dichroic beamsplitter (DBS2) separates the infrared from the visible light. In the remaining green beam an intensity beamsplitter (IBS1) reflects $1 \%$ of the green light intensity onto an energy meter $\left(\mathrm{E}_{532}\right)$ to continuously monitor the beam energy during operation. The laser light at $532 \mathrm{~nm}$ wavelength is linearly polarised by more than $99 \%$. As the depolarisation measurements are calibrated by normalising to the depolarisation of the air molecules, which is only $0.4 \%$ for the filter bandpath of our detectors, a cleanup of any residual depolarisation is required. This is achieved with a Brewster plate (BP), which reflects any light which does not have the desired polarisation direction, onto an absorber (As1). A detailed analysis shows the instrumental depolarisation to be compatible with zero (Blum, 2003). This precise state of beam polarisation meets the requirements for depolarisation measurements. Next, a beam widening telescope (BWT) expands the green beam from a 9-mm diameter by a factor of 10 to a $9-\mathrm{cm}$ diameter, which leads to a reduction of the beam divergence from $500 \mu \mathrm{rad}$ to $50 \mu \mathrm{rad}$, which is equivalent to a spot of $5 \mathrm{~m}$ in diameter in $100 \mathrm{~km}$ altitude. This reduction of the beam divergence enables us to use a smaller field of view for the receiver and thus to reduce the solar background, which is a second requirement to perform daylight measurements. Finally, a steerable mirror (M4) directs the beam vertically in the atmosphere. This mirror is tiltable in two perpendicular axes which allows 
Table 2. Characteristics of transmitted light.

\begin{tabular}{|c|c|c|c|}
\hline \multicolumn{4}{|c|}{ two color operational mode } \\
\hline wavelength & $1064 \mathrm{~nm}$ & $532 \mathrm{~nm}$ & \\
\hline pulse energy & $420 \mathrm{~mJ}$ & $600 \mathrm{~mJ}$ & \\
\hline polarisation & linear (hor) & linear (ver) & \\
\hline beam-diameter & $27 \mathrm{~mm}$ & $90 \mathrm{~mm}$ & \\
\hline beam-divergence & $190 \mu \mathrm{rad}$ & $50 \mu \mathrm{rad}$ & \\
\hline \multicolumn{4}{|c|}{ three color operational mode } \\
\hline wavelength & $1064 \mathrm{~nm}$ & $532 \mathrm{~nm}$ & $355 \mathrm{~nm}$ \\
\hline pulse energy & $250 \mathrm{~mJ}$ & $330 \mathrm{~mJ}$ & $180 \mathrm{~mJ}$ \\
\hline polarisation & elliptical & linear (ver) & linear (hor) \\
\hline beam-diameter & $27 \mathrm{~mm}$ & $90 \mathrm{~mm}$ & $27 \mathrm{~mm}$ \\
\hline beam-divergence & $190 \mu \mathrm{rad}$ & $50 \mu \mathrm{rad}$ & $190 \mu \mathrm{rad}$ \\
\hline
\end{tabular}

an alignment of the emitted beam in azimuth and elevation, to be used to steer the laser beam into the field of view of the telescopes. The infrared light which was separated from the green light by the dichroic beamspliter (DBS2) is directed by the mirror M5 into another optical branch which is optimised for infrared and ultraviolet light. This branch is also used in the three color mode for the infrared and ultraviolet light.

In the case of the three color operational mode the mirror M1 in front of the THG is moved out of the mixed visible/infrared beam with the movable sledge (MSL1) and the beam follows the path marked by the dotted lines in Fig. 1 . Directly behind the THG a dichroic beamsplitter (DBS1) and a mirror (M3) direct the green light out of the beam onto the green light path of the two color mode. The mirror M3 is positioned by a second movable sledge (MSL2). The infrared light $(1064 \mathrm{~nm})$ and the ultraviolet light $(355 \mathrm{~nm})$ leave the laser housing in a single beam. A dichroic beamsplitter (DBS3) removes any remaining green light from the beam and directs it to an absorber (As2) to avoid contamination of the polarisation measurements. The energy of the $355 \mathrm{~nm}$ light is monitored by an energy meter $\left(\mathrm{E}_{355}\right)$, which receives light from an intensity beamsplitter (IBS2, 1\%). Following the IBS2 a two-color beam widening telescope (BWT) for 355-nm and 1064-nm wavelengths expands the 9-mm diameter beam by a factor of three. As daylight measurements are performed on the 532-nm wavelength only, a larger reduction of beam divergence is not necessary for the UV/IR branch. Following the BWT a steerable mirror (M6) reflects the 1064-nm and 355-nm light vertically into the atmosphere. This mirror is also tiltable in azimuth and elevation which is used to align the laser beam within the telescope's field of view. The main characteristics of the transmitted light are summarised in Table 2. The movable sledges (MSL1+MSL2) allow a fast change-over from the $2-\lambda$ to the $3-\lambda$ configuration. This maximises the efficiency of the lidar system in case that there are no PSCs or that aerosol size estimation is not planned.

\section{Receiver}

To permit observations of the desired geophysical parameters the receiver has to meet several requirements. These are the registration of atmospheric signals covering 7-8 orders of magnitude, the separation and detection of different wavelengths and polarisations, a narrow-band filtering system for daylight measurements, and a fast switching from daylight to nighttime configuration and vice versa. The receiver of the U. Bonn lidar consists of the telescope part collecting and separating the backscattered light according to polarisation and wavelengths, on the one hand, and of the optical bench where the light pulses are converted into electric signals, on the other hand.

\subsection{Telescopes and focal boxes}

The U. Bonn lidar uses three Newtonian telescopes the primary mirrors of which have a diameter of $50.8 \mathrm{~cm}$ and a focal length of $254.0 \mathrm{~cm}$. The total mirror area is equivalent to one mirror of $86.6 \mathrm{~cm}$ in diameter. The laser beam is emitted at the center of the 3-mirror triangular arrangement, which is a quasi-monostatic lidar geometry with an offset of $35 \mathrm{~cm}$ from the beam to the individual mirror centers. The collected light is directed by a flat secondary mirror into one focal box for each telescope. The use of three individual telescopes increases the flexibility of the lidar. If identical focal boxes are fitted to the telescopes, the total signal is maximised. However, it is possible to attach different focal boxes to the telescopes, which are optimised for different wavelengths. For example, in January/February 1999 the focal box of one of the telescopes was optimised for receiving the rotational Raman signal from the air, which was passed to the GKSS Raman detector to obtain temperatures in the presence of aerosols and clouds in the upper troposphere and lower stratosphere (Behrendt et al., 1999). For high reaching UV-measurements the use of an optimised focal box is essential, too. The transmission of the second optical element, a polarisation cube, is well below $10 \%$ in the ultraviolet. Thus, measurements at 355-nm wavelength of good quality have to be performed with a single telescope without the polarisation cube in the focal box.

The standard focal box is designed to separate the received signals according to the planes of polarisation and to wavelengths. The schematics for a focal box is given in Fig. 2. The entrance aperture (Ap) of the focal box sits in the focal plane of the primary mirror. Its diameter is $1 \mathrm{~mm}$ for nighttime operations and can be reduced to $0.6 \mathrm{~mm}$ for daylight operations, with the low divergence green light to minimise the stray light from the sky. The full angular diameters of $0.4 \mathrm{mrad}$ and $0.24 \mathrm{mrad}$, respectively, exceed the laser beam divergence by factors of up to 5 , allowing for a safe overlap. Following the aperture an achromatic lens (L1) with an $\mathrm{MgF}_{2}$ coating causes the incoming beam to become parallel. The coating offers a transmission of about $90 \%$ in the whole wavelength range from the infrared $(1064 \mathrm{~nm})$ to the ultraviolet $(355 \mathrm{~nm})$. As dichroic beamsplitters disturb the 


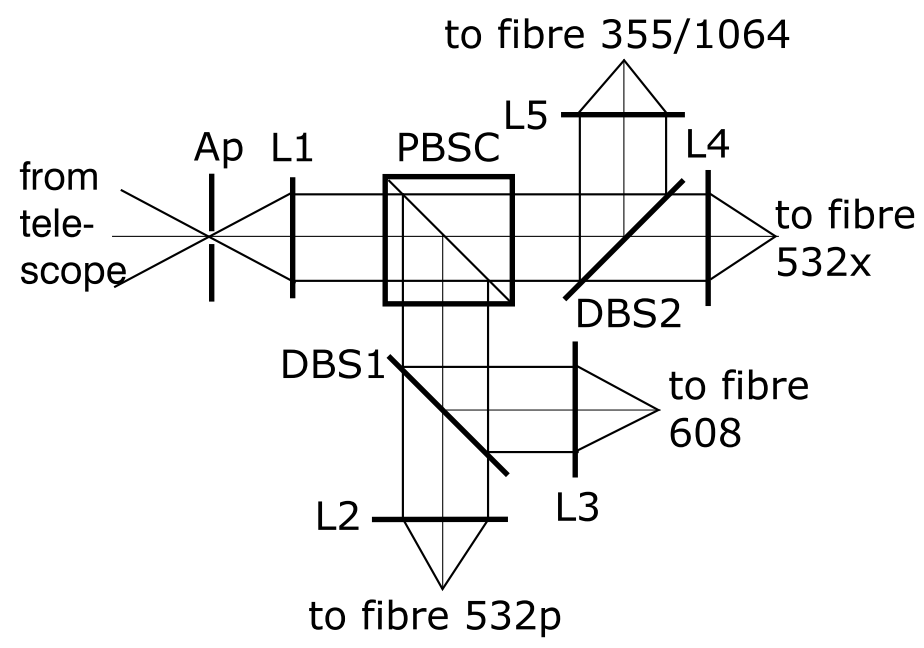

Fig. 2. Optical setup of a focal box. See text for details.

polarisation characteristics of light, polarisation separation is the first step in the analysis of the light reflected from the atmosphere. The part of the incoming light which has a polarisation perpendicular to the emitted laser light at 532$\mathrm{nm}$ wavelength (cross polarised light) passes through the polarisation beam splitter cube (PBSC) in the beam direction, whereas the light in the plane of polarisation of the emitted green light (parallel polarised light) is reflected out of the beam. In this parallel polarised beam a dichroic beamsplitter (DBS1) separates the green light at 532-nm wavelength from the vibrational-Raman light of molecular nitrogen $\left(\mathrm{N}_{2}\right)$ at $608 \mathrm{~nm}$ and consecutive lens systems (L2, L3) focus the light into optical fibres. The polarisation beamsplitter cube is optimised for a band of about $\pm 150 \mathrm{~nm}$ around $532 \mathrm{~nm}$. Hence, the UV-light at 355-nm and the IR-light at 1064-nm wavelength are transmitted through the cube coinciding with the cross-polarised component of the VIS-532 $\mathrm{nm}$ beam. The IR and UV component of the transmitted beam are separated from the VIS beam with a dichroic beamsplitter (DBS2) and both beams are focused by lens systems (L4, L5) to fibres. In total 4 fibres leave each focal box for the different wavelengths and polarisation directions. The fibres have a quartz core with a quartz cladding and a numerical aperture of NA=0.22. The cores of the fibres for $532-\mathrm{nm}$ and $608-\mathrm{nm}$ light have a diameter of $365 \mu \mathrm{m}$, whereas those for $355-\mathrm{nm}$ and 1064-nm light have $545 \mu \mathrm{m}$. This larger diameter of the $355 / 1064 \mathrm{~nm}$ fiber corresponds to the larger divergence of the emitted infrared/ultraviolet beam. The imaging optics in the focal box transform the numerical aperture of the telescope $(\mathrm{NA}=0.1)$ to that of the fibres $(\mathrm{NA}=0.22)$, to avoid loss of light and pickup of stray light. The telescopes, as well as the focal boxes are situated in a telescope hut, the roof of which is opened during operations and thus exposes the telescope structure to ambient temperatures.

Altogether there are 12 signal fibres from the telescopes, four alignment fibres, eight stepper motors for the remotelycontrolled alignment of the laser beam with the field of view of the telescopes and four further motors for the covers of the telescopes and the focal box shutters. The mechanical structure of the complete telescope system was built at the institute workshop.

\subsection{Optical benches}

For each color and polarisation there is a specialised optical bench. The three individual fibres from each telescope are merged into one fibre bundle for each color and polarisation. The simplest configuration is employed for the vibrationalRaman branch at 608-nm wavelength. Two lenses are used to generate a parallel beam from the fibre bundle, which passes through an interference filter and which is focussed onto the photocathode of a photomultiplier. Slightly more elaborate is the UV/IR-branch as the two wavelengths $355 \mathrm{~nm}$ and $1064 \mathrm{~nm}$ are being fed to this optical bench. Following the injecting lenses a dichroic beamsplitter divides the UV- and IR-light by reflecting the UV-light perpendicular out of the beam. The IR-light travels via an interference filter through another lens on a photomultiplier. The reflected UV-light is filtered by an interference filter, then cascaded with a $10 \%$ intensity beamsplitter, and finally focused on two photomultipliers.

The most complicated setups are used for the two 532-nm optical benches. The schematics for the 532-nm parallel polarisation bench is shown in Fig. 3. The incoming light is made parallel into a 39-mm diameter beam by a lens system (L1). This large beam diameter is necessary to meet the divergence requirements for the fixed-spacer etalons $(\mathrm{Et})$, one of which is located in each green optical bench on a movable sliding stage (MSL) so that it is easy to switch between daylight and nighttime configurations for both polarisation directions. The etalons are density tuned, i.e. the spectral alignment to the central wavelength (CWL) is achieved by adjusting the refractive index in the pressure chamber where the etalons are located. Thus, the orientation of the etalons can be held perpendicular to the direction of the incoming 


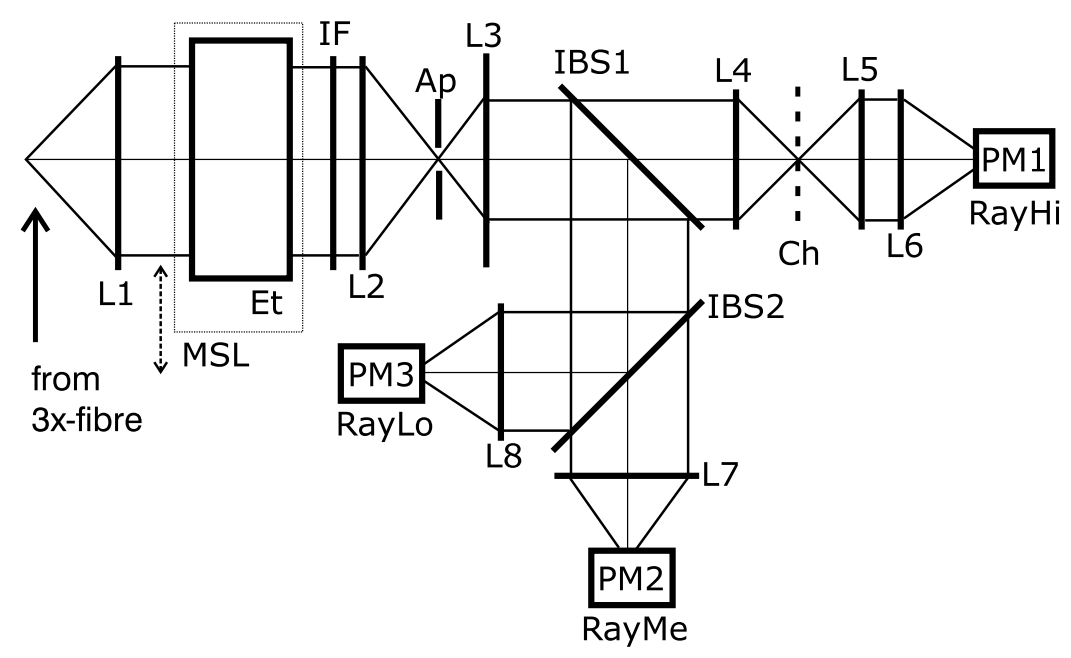

Fig. 3. Optical setup of the optical bench on 532-nm parallel polarisation. See text for details.

Table 3. Characteristics of the etalons in the 532-nm channels.

\begin{tabular}{rccc}
\hline Branch & FWHM /pm & FSR / pm & Transmission/\% \\
\hline $532_{\|}$ & 4.8 & 120.0 & 25 \\
$532_{\perp}$ & 5.9 & 148.1 & 25 \\
\hline
\end{tabular}

Table 4. Characteristics of cascaded detection in the 532-nm channels.

\begin{tabular}{|c|c|c|}
\hline $532_{\|}$ & $\begin{array}{r}\text { double cascade: } \\
\text { RayHi (PM1) }\end{array}$ & $\begin{array}{r}1: 10: 100(\mathrm{IBS} 1, \mathrm{IBS} 2) \\
\text { mechanical chopper }(\mathrm{Ch}) \\
\text { suppression of } \approx 10^{6} \\
\text { suppressing lowermost } 15-30 \mathrm{~km} \\
\text { electro-optical shutter } \\
\text { suppression of } \approx 3 \cdot 10^{2} \\
\text { suppressing lowermost } 8-12 \mathrm{~km} \\
\text { neutral density filter } \\
\text { attenuation of } \approx 10^{1}\end{array}$ \\
\hline $532 \perp$ & $\begin{array}{r}\text { single cascade: } \\
\text { RayXH }\end{array}$ & $\begin{array}{r}1: 10 \\
\text { electro-optical shutter } \\
\text { suppression of } \approx 3 \cdot 10^{2} \\
\text { suppressing lowermost } 8-12 \mathrm{~km} \\
\text { no attenuator }\end{array}$ \\
\hline
\end{tabular}

Abbreviations (PM1, PM2, PM3, IBS1, IBS2) are according to Fig. 3. RayXH and RayXL refer to the high and low sensitive channel in perpendicular polarisation.

light, which maximises the transmission. Together with the interference filter (IF), which blocks the adjacent transmission maxima of the etalon, a narrow-band filtering system is achieved. The characteristics of the etalons are shown in Table 3. The beam diameter in the parallel channel is reduced by an inverted Kepler telescope (L2+L3) to ease further beam handling. In the focal plane of the Kepler telescope an aperture (Ap) reduces stray beams from multiple reflections on optical surfaces. In the perpendicular channel an inverted Galileo telescope directly in front of the photomultiplier of the most sensitive channel reduces the beam diameter.

To cover the large dynamical range of 7-8 orders of magnitude in the parallel polarised channel and of 6-7 orders of magnitude in the cross polarised channel, both green channels are cascaded and the individual photomultipliers are protected against high levels of light from the troposphere and lower stratosphere. To obtain a clearly defined transition between the blocked and opened light path in the high sensitivity channel (RayHi), the light spot in the plane of the chopper wheel is made very small with an aspherical condenser lens (L4). To revert to a parallel beam a second condenser lens (L5) is used. The characteristics of the cascaded detection system are collected in Table 4.

In each detection channel the light is finally focused by a lens (L6, L7, L8) on a photomultiplier. The characteristics of the different receiver branches are summarised in Table 5. Signal processing from the nine photomultipliers follows nuclear instrumentation techniques using NIM (nuclear instrument method) and CAMAC (computer automated measurement and control) standards. The photomultiplier signals are amplified by $300-\mathrm{MHz}$ bipolar preamplifiers (Phillips-Scientific, PS 6950), converted to NIM pulses by $300-\mathrm{MHz}$ discriminators (Phillips-Scientific, PS 708 ), and counted by $150-\mathrm{MHz}$ dead-timeless counters with storage memory (Joerger, S3). Each electronic detection chain acts as a paralysing counting system with an overall dead time of about $10 \mathrm{~ns}$. The minimum vertical resolution of the counters is $1 \mu \mathrm{s}$, which is equivalent to a range gate of $150 \mathrm{~m}$ width. The counters, as well as the discriminators, are mounted in a CAMAC crate. A synchronisation unit was designed and built by the electronic workshop of the institute. This unit draws power from the CAMAC backplane and it receives a signal from a photodiode which determines the position of the chopper wheel. Depending on this signal the synchronisation unit switches the electro-optical shutters, it 
Table 5. Characteristics of the receiver branches.

\begin{tabular}{lccccc}
\hline channel & $532 \|$ & $532 \perp$ & 608 & 355 & 1064 \\
\hline filter CWL / nm & 532.13 & 532.13 & 608.36 & 355 & 1064 \\
filter width / nm & 0.12 & 0.13 & 3.00 & 1 & 10 \\
altitude range / km & $4-100$ & $4-60$ & $4-50$ & $4-90$ & $4-30$ \\
number/type of PM cathode & $3 /$ bi-alkali & $2 /$ bi-alkali & $1 /$ cooled GaAs & $2 /$ bi-alkali & $1 /$ cooled S1 \\
daylight capability & yes & yes & no & no & no \\
\hline
\end{tabular}

initiates charging the flashlamps of the laser, and it fires the laser. With each emitted pulse the laser triggers the counters. When all counters have completed data collection (up to $1 \mathrm{~ms}$ or $150 \mathrm{~km}$ ) a Fortran control program accesses the CAMAC bus and tranfers the data to a MS-DOS-based computer. There is no pre-summation in the counting electronics and each laser shot can be processed individually. Typically, 5000 laser shorts are accumulated and stored to disk, which results in an integration time of about 5 minutes. Shorter integration times can easily be achieved by storing fewer laser shots to disk.

\section{Instrument performance}

In this section the performance of the lidar instrument will be demonstrated w.r.t. the initially defined requirements. In a first step emphasis is placed on the technical behaviour of the instrument during operations and in a second step the geophysical capabilities are discussed.

\subsection{Technical performance}

The overview on the technical performance of the instrument focuses on the stability of the instrument during operations and the efficiency for daylight operations. Before going into the details of the instrument's performance, the overall efficiency of the complete lidar system is described.

\subsubsection{Overall lidar performance}

The overall performance of the lidar can be estimated by, for example, the number of photon counts received per laser pulse and 1-km altitude interval from a reference altitude on a 532-nm wavelength in parallel polarisation. We have chosen $30 \mathrm{~km}$ as a reference altitude, because the backscattered light from this altitude comes from Rayleigh scattering on air molecules and the aerosol content is negligible. Additionally, the received signal from this altitude is still very strong. The received photon count number is normalised to the pulse energy of the laser and to the telescope area. This number we define as the normalised photon counts (NPC).

The atmospheric number density at $30 \mathrm{~km}$ altitude is about $2.8 \cdot 10^{17} \mathrm{~cm}^{-3}$ (Hedin, 1991) and the backscatter cross section is about $6.2 \cdot 10^{-28} \mathrm{~cm}^{2} \mathrm{sr}^{-1}$ (Nicolet, 1984). Assuming $100 \%$ transmission in the atmosphere and in the receiving
Table 6. Transmission and efficiency $\varepsilon$ of the receiving system at $532-\mathrm{nm}$ wavelength in parallel polarisation. Abbreviations are according to Figs. 2 and 3.

\begin{tabular}{|c|c|}
\hline Device & $\varepsilon / \%$ \\
\hline Telescope: & 75 \\
\hline Primary mirror & 85 \\
\hline Secondary mirror & 88 \\
\hline Focal box (Fig. 2): & 78 \\
\hline lens L1 (MgF coated) & 90 \\
\hline polarisation beam splitter PBSC & 99 \\
\hline dichroic beam splitter DBS1 & 95 \\
\hline lens system L3 (2 lenses, AR-coated) & 96 \\
\hline glass-fibre incoupling & 96 \\
\hline Glass-fibre: & 98 \\
\hline Optical bench (Fig. 3): & 3.5 \\
\hline glass-fibre outcoupling & 96 \\
\hline lens system L1 (2 lenses, un-coated) & 85 \\
\hline interference filter IF & 46 \\
\hline Kepler telescope L2+L3 (un-coated) & 85 \\
\hline intensity beam splitter IBS1 & 90 \\
\hline aspheric condenser lenses L4+L5 (AR-coated) & 96 \\
\hline lens L6 (un-coated) & 92 \\
\hline PM tube (un-coated) & 92 \\
\hline photocathode & 15 \\
\hline Overall detection efficiency: & 2.0 \\
\hline
\end{tabular}

optics, the return signal from the atmosphere is expected to be NPC $\approx 50000 \mathrm{cts} /\left(\mathrm{km} \cdot \mathrm{J} \cdot \mathrm{m}^{2}\right)$. The transmission and efficiency $\varepsilon$ of the receiving system (telescope, glass-fibre, optical bench, and photomultiplier) can be estimated to be $\varepsilon \approx 2.0 \%$ (Table 6), resulting in an expected signal of $\mathrm{NPC} \approx 1000 \mathrm{cts} /\left(\mathrm{km} \cdot \mathrm{J} \cdot \mathrm{m}^{2}\right)$. The atmospheric transmission is influenced by the Rayleigh extinction resulting in an optical thickness of $\tau_{\text {Ray }}=0.11$ and a transmission of $\varepsilon=90 \%$ on the one hand. On the other hand the atmospheric transmission is determined by the scattering on aerosols. The aerosol optical properties depend crucially on the air mass type as e.g. Arctic, polar or tropical (Smirnov et al., 1994). Although there are no measurements of the aerosol optical properties above the Esrange available, it can be assumed that the air masses above the Esrange will be predominately Arctic and polar. Thus, an aerosol optical depth of $\tau_{A e r} \approx 0.15$ 
can be assumed (Smirnov et al., 1996), which leads to a transmission of $\varepsilon \approx 86 \%$. Thus, the two-way overall atmospheric transmission can be estimated to be $\varepsilon \approx 60 \%$ which leads to an expected signal of NPC $\approx 600 \mathrm{cts} /\left(\mathrm{km} \cdot \mathrm{J} \cdot \mathrm{m}^{2}\right)$. The actual best signal received with the $\mathrm{U}$. Bonn lidar is $\mathrm{NPC}=340 \mathrm{cts} /\left(\mathrm{km} \cdot \mathrm{J} \cdot \mathrm{m}^{2}\right)$. The difference of about $50 \%$ between the expected and the measured value is acceptable, since in the theoretical calculations a perfect alignment and complete clean optics are assumed, which is not achievable. Similar lidar experiments reach a comparable best signal of $\mathrm{NPC}=300-400 \mathrm{cts} /\left(\mathrm{km} \cdot \mathrm{J} \cdot \mathrm{m}^{2}\right)(\mathrm{v}$. Zahn, personal communication, 2001).

\subsubsection{Stability}

The overall technical performance of the lidar instrument is very good. Except for standard maintenance, such as changing the flashlamps or the cooling water, the laser works well during summer and winter without undue attention. A decrease in the output energy to about $75 \%$ of the nominal energy can be observed with increasing deterioration of the flashlamps. The stability of the spectral alignment of the daylight etalons by the pressure chambers turns out to be better than $1 \%$ for at least half a year.

For a 3-telescope system aligning the laser beam with the receiver's field of view (FOV) involves two tasks: one is to assure that the individual FOV of the telescopes are identical (bore-sighted), and the other is to assure that the laser beam is inside the common FOV of the telescopes. The basic operation for both tasks is to scan the laser beam with steering mirrors M4 (for $532 \mathrm{~nm}$ ) and M6 (for 355/1064 nm) in azimuth and elevation across the FOV of one telescope, or a combination of them, and to observe the signal from a preset altitude range - typically 30 to $40 \mathrm{~km}$. The optimum position is defined by the maximum of this signal. If the task is to obtain a common FOV for the telescopes, the signal from each telescope is inspected separately. First, the laser beam is aligned with the fixed FOV of the reference telescope by adjusting the base position of the beam steering mirror. Next, the direction of the FOV of the second telescope is changed by moving its focal box perpendicular to the telescope optical axis with stepper motors until the signal optimum coincides with that of the reference telescope. The third telescope is treated correspondingly. The common FOV alignment is usually stable for at least a week.

The second task, to align the laser beam within the common FOV of the telescopes, needs attention much more frequently. In response to changes in temperature of the telescope structure the struts which prevent an oscillation of the platform, on which the beam steering mirrors are mounted, expand or contract, leading to a slight angular tilt of this platform and hence the laser beam. After exposing the telescope to the ambient temperatures in the range from $-45^{\circ} \mathrm{C}$ to $+30^{\circ} \mathrm{C}$ alignment checks are required every half hour. The requirement continuously relaxes to several hours as the telescope structure attains thermal equilibrium with the ambient atmosphere. During very long measurement runs beam alignment needs attention primarily during sunset and sunrise.

\subsubsection{Daylight operations}

For the detection of weak aerosol layers during daylight an effective supression of the solar background signal is necessary. The noise of this background signal follows Poisson statistics and is given by the square root of the signal. To detect a weak aerosol signal unambiguously, the aerosol signal must be larger than the noise of the background signal. In particular, NLC layers are identified as aerosol if the NLCsignal is larger than the 3- $\sigma$ noise level of the background signal. The improvement of the signal-to-noise ratio is obtained with an etalon as spectral filter, for which Fig. 4 shows an example.

The data were obtained on 18 July 2004 with and without etalon. The solar elevation during the measurements was about $11^{\circ}$. The solid line represents the background subtracted lidar signal and the dashed line represents the 3- $\sigma$ noise level of the background. In the left, as well as in the right plot, a NLC can be detected, however, the NLC in the left plot (with etalon) is much clearer than in the right plot (without etalon). The backscatter coefficients of the NLCs are similar with $\beta=(5.4 \pm 0.6) \cdot 10^{-6} 1 /(\mathrm{km} \cdot \mathrm{sr})$ for the left plot and $\beta=(3.2 \pm 0.6) \cdot 10^{-6} 1 /(\mathrm{km} \cdot \mathrm{sr})$ for the right plot. From the NLC signal and the 3- $\sigma$ noise value of the background we can deduce the detection threshold of $\beta=(1.2 \pm 0.5) \cdot 10^{-6} 1 /(\mathrm{km} \cdot \mathrm{sr})$ for measurements with etalon and of $\beta=(1.9 \pm 0.6) \cdot 10^{-6} 1 /(\mathrm{km} \cdot \mathrm{sr})$ for measurements without etalon in this given measurement conditions. This corresponds to nearly a factor 2 improvement for the sensitivity of NLC detection in $5 \mathrm{~min}$ integration time.

\subsection{Geophysical capabilities}

The overview of the geophysical capabilities of the instrument embraces the coverage of the whole atmosphere from nearly the ground up to the mesopause, the detection of different aerosols, and the potential for temperature calculation, as well as the analysis of atmospheric gravity waves.

\subsubsection{MST-lidar}

With the intensity cascades for the backscattered signal in the visible and ultraviolet detection channels the lidar is able to cover all the atmosphere from about the ground up to the mesopause, or even higher. Because of the quasi-monostatic lidar configuration the overlap between the laser beam and the field of view of the telescopes is complete only above $4 \mathrm{~km}$ altitude. Figure 5 gives an example of raw data from the lidar, operated in the 2-colour mode on 20/21 January 2004 between 22:12 UT and 08:27 UT.

The most intense signal appears in the parallel polarised channel at 532-nm wavelength. This channel covers the whole atmosphere from about $4 \mathrm{~km}$ up to $90 \mathrm{~km}$ altitude. The complete picture over the whole range is obtained by normalising the cascaded channels to the most sensitive one and 

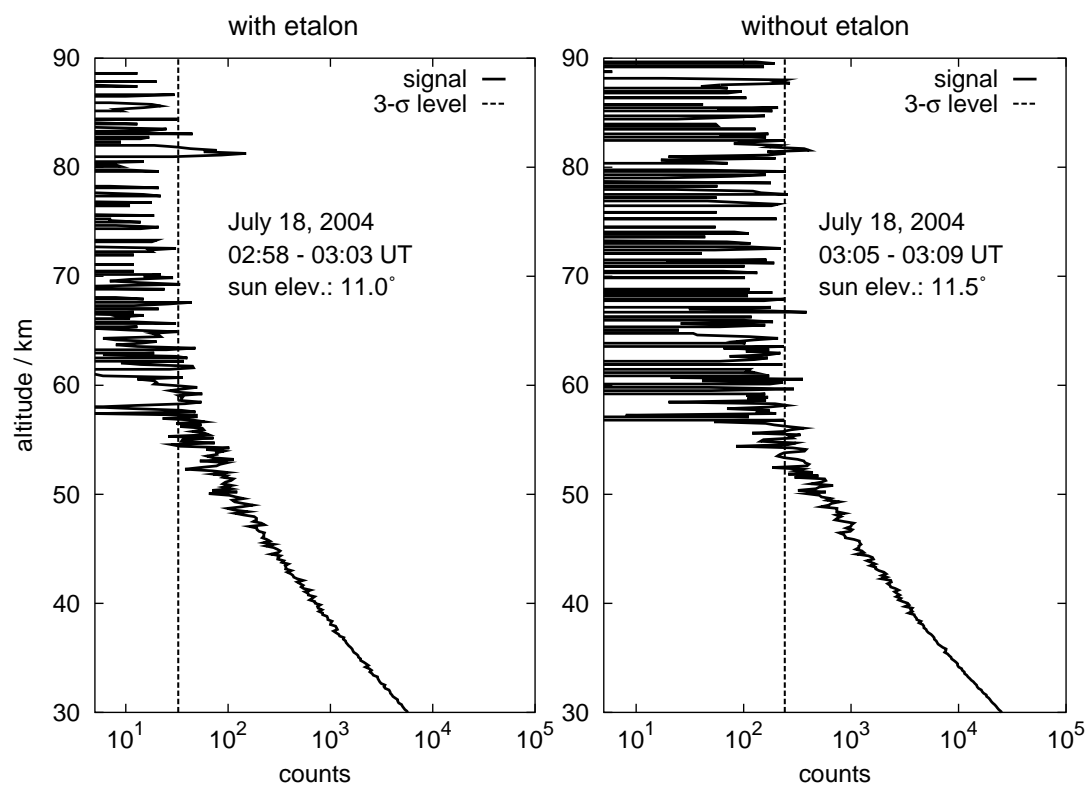

Fig. 4. Lidar observation of a noctilucent cloud during daylight conditions. The left plot shows data using an etalon as daylight filter, whereas the right plot shows data taken without etalon filtering. The measurements are from 18 July 2004 , at a solar elevation angle of $11^{\circ}$. The solid lines represent the background subtracted lidar data. The dashed line is the 3- $\sigma$ level of the background signal.

merging them. The cascade then properly spans the eight orders of magnitude in dynamic range, caused by the atmosphere, in combination with the $1 / \mathrm{r}^{2}$-dependence of the lidar signal, due to geometrical effects. The cross polarised channel on 532-nm wavelength reaches up to $60 \mathrm{~km}$, which is well above the stratopause. The vibrational-Raman signal on 608-nm wavelength reaches nearly up to the stratopause. The different altitudes reached for these three signals, associated with the emitted intensity at $532 \mathrm{~nm}$, primarily reflects the differences in the backscatter cross sections, which are $1 / 300$ and 1/1000 smaller for the cross-polarised signal and the vibrational Raman signal than that for the parallel channel. The signal of the infrared channel on $1064 \mathrm{~nm}$ covers the lower stratosphere up to $30 \mathrm{~km}$ altitude.

\subsubsection{Aerosol detection}

Due to the wide coverage of the atmosphere by the green channel, cloud observations in the troposphere, stratosphere, and mesosphere are possible. Tropospheric clouds, in particular cirrus clouds, can be observed during the entire year. In winter polar stratospheric clouds occur at these latitudes in the lower and middle stratosphere and during polar summer noctilucent clouds occur around the mesopause. Additionally, in the infrared channel, which offers the highest sensitivity to aerosol particles, the stratospheric background aerosol can be observed regularly during darkness. One measure of aerosols is the backscatter ratio (BSR), which is defined as the total backscattered signal from an altitude $\mathrm{z}$ divided by the molecular signal from this altitude. The molecular signal can either be retrieved from the vibrational-Raman signal or taken from an atmospheric model. During winter the Raman method is favoured in the troposphere and strato-

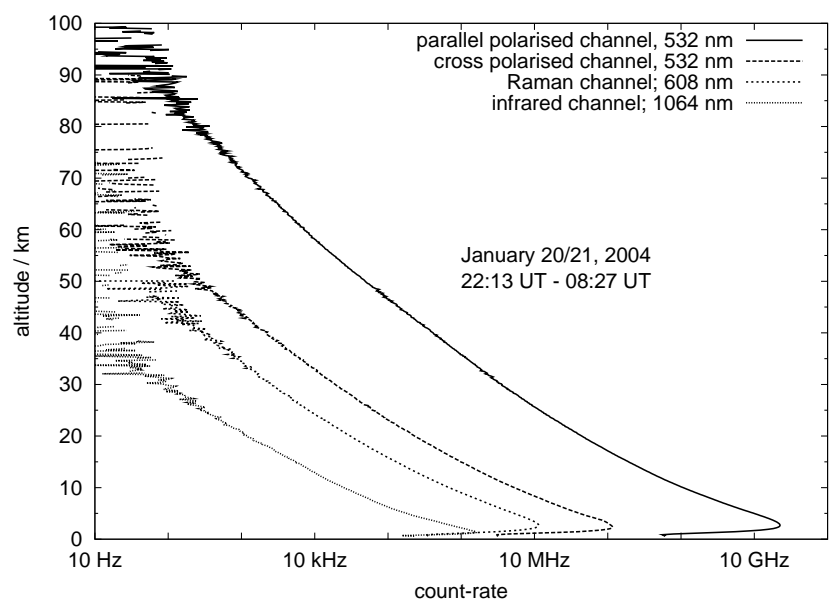

Fig. 5. Lidar raw data from $20 / 21$ January 2004 in $2-\lambda$ configuration. Shown are data of parallel polarised and the cross polarised channel at 532-nm wavelength, data of the vibrational-Raman channel at $608-\mathrm{nm}$ and of the infrared channel at 1064-nm wavelength. The cascaded green channels are fitted to the most intensive in each polarisation and afterwards merged. Thus, high count rates of $10 \mathrm{GHz}$ and more can be observed.

sphere. In summertime and during daylight - which are the basic conditions for NLC measurements - the Raman channel is not available. We then take atmospheric density data from a statistical model for northern Scandinavia based on falling sphere data (Lübken, 1999). Another possibility to describe the aerosol content of the atmosphere is the backscatter coefficient, which is defined as

$\beta(z)=(B S R(z)-1) \cdot n(z) \sigma_{\pi}$, 

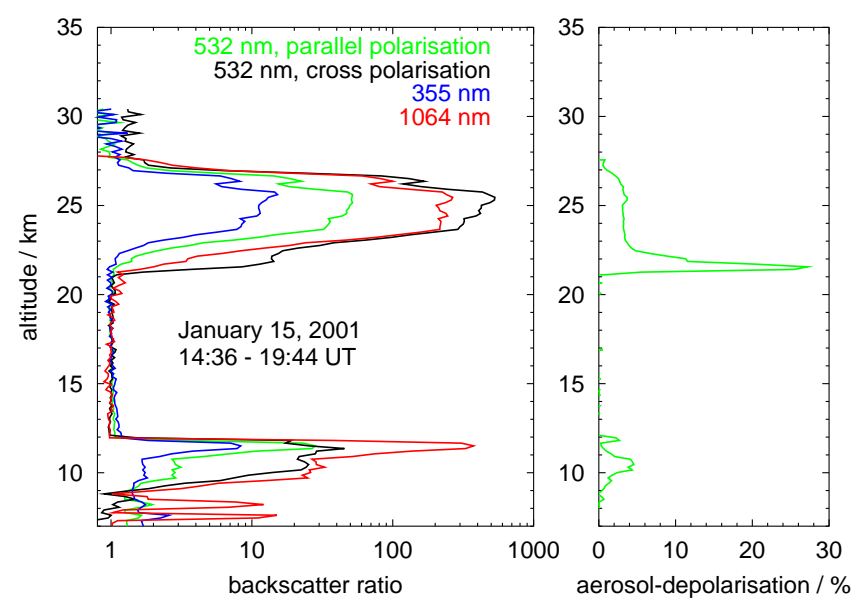

Fig. 6. Lidar observation of a polar stratospheric and a cirrus cloud on 15 January 2001. Shown are the backscatter ratio in the parallel and cross polarised channel at 532-nm wavelength, at $355 \mathrm{~nm}$, and at $1064 \mathrm{~nm}$ (left), as well as the aerosol depolarisation (right).

where $B S R(z)$ is the backscatter ratio, $n(z)$ the molecular number density in the altitude $z$, and $\sigma_{\pi}$ the known backscatter cross section of the air molecules. A second measure of aerosols is the aerosol depolarisation, which is defined as the ratio of the aerosol signal in the cross polarised channel and in the parallel polarised channel. Both quantities together allow, for example, a classification of the observed PSC (Browell et al., 1990; Toon et al., 2000) or a size estimate of cirrus cloud or PSC particles (Sassen, 1991; Blum et al., 2001). Figure 6 shows backscatter ratios and aerosol depolarisation of a PSC and cirrus observation on 15 January 2001. In the altitude range from $21-28 \mathrm{~km}$ the signal of the polar stratospheric cloud is observable in all four channels. The large values of the BSR in the green channels indicate that the cloud consists mostly of water-ice. The large aerosol depolarisation at the lower wings of the PSC shows that a thin layer of nitric acid trihydrate (NAT) exists in this altitude. In the altitude $9-12 \mathrm{~km}$ the signature of a high cirrus cloud is observable. Again, the high values of the backscatter ratio in the green channels show that the cirrus also consists of water ice. Below the cirrus a smaller aerosol contribution can be found to which the infrared channel is most sensitive.

During the years 1997-2004 there were more than $2000 \mathrm{~h}$ of measurements during winter, including more than $300 \mathrm{~h}$ of PSC. A classification of the observed PSCs revealed that $15 \%$ of these clouds can be attributed to NAT-particles, $37 \%$ to STS-particles (Supercooled Ternary Solution), and 9\% to water-ice clouds. The remaining 39\% must consist out of a mixture of solid (NAT) and liquid (STS) particles. The analysis of the corresponding temperature and wind data provided by the European Centre for Medium-range Weather Forecast (ECMWF) showed that more than $80 \%$ of the observed PSCs need leewave-induced cooling of the atmosphere for existence (Blum et al., 2005).
The detection limit for PSC is not determined by the instrument's sensitivity but by the signal strength of the background aerosol. At a BSR of 1.06 in the parallel polarisation the PSC is not distinguishable from the background aerosol. Even during bad measurement conditions under semi-clouded sky (optical thickness of the troposphere $\tau \approx 2.5$ ), PSCs can be detected in the parallel polarisation with about $0.5 \%$ precision, and in the perpendicular polarisation channel with about $10 \%$ precision within 5 -min integration time.

A summer measurement of a NLC is shown in Fig. 7. During 22/23 July 2004 a NLC was observed from 17:00 UT to 10:00 UT. The solar elevation varied during the observation time from $+40^{\circ}$ to $-2^{\circ}$, thus the measurements were carried out during daylight conditions using the etalon for daylight filtering. During the darkest time (19:00-01:00 UT), the integration time could be reduced, i.e. the temporal resolution is better, as can be seen from the asterisks at the top of the plot which mark the data sets used. The lidar detects the large variation in brightness $(\beta)$, width, and altitude of the NLC.

Since 1997 there were about $800 \mathrm{~h}$ of lidar measurements during summer, including about 110 hours of NLC observations during 27 days. The detection limit for NLCs strongly depends on the solar elevation angle, the tropospheric transmission, and the integration time. As shown in Sect. 5.1.3 the detection limit for NLCs is at a backscatter coefficient of $\beta \approx 1-2 \cdot 10^{-6} 1 /(\mathrm{km} \cdot \mathrm{sr})$ in 5 -min integration time during daylight.

\subsubsection{Atmospheric temperatures and gravity waves}

In the aerosol free part of the atmosphere the data from the 532-nm wavelength channels can be used to calculate an atmospheric temperature profile. Assuming hydrostatic equilibrium, the integration of the range corrected lidar net signal yields the temperature profile. At the upper end of the profile a seed temperature has to be estimated, which we take from the MSISE90 model (Hedin, 1991). Below 30$\mathrm{km}$ altitude, where usually background aerosol exists, the vibrational-Raman channel can be used if the transmission losses due to aerosols is very low. The signal of this channel is determined by the molecular nitrogen available in the atmosphere and thus gives a pure molecular signal, free of any aerosol contribution. Below 30-km altitude the extinction due to molecules and ozone cannot be neglected any more. Thus, a correction on the 608-nm Raman signal must be included in the data analysis. Figure 8 shows a temperature profile derived from U. Bonn lidar data and the temperature profile measured by a radiosonde on 16 January 2002 . Whereas the lidar covers the time from 0:00 UT-07:00 UT, the radiosonde was launched during this measurement run at 05:00 UT.

During a time interval of seven hours, the temperature profile can be determined from $15 \mathrm{~km}$ to $85 \mathrm{~km}$ altitude. The temperature error of the lidar is also plotted. At about 35$\mathrm{km}$ altitude a step in the error occurs, which is caused by the change in the lidar channel. Above $35-\mathrm{km}$ altitude the most 


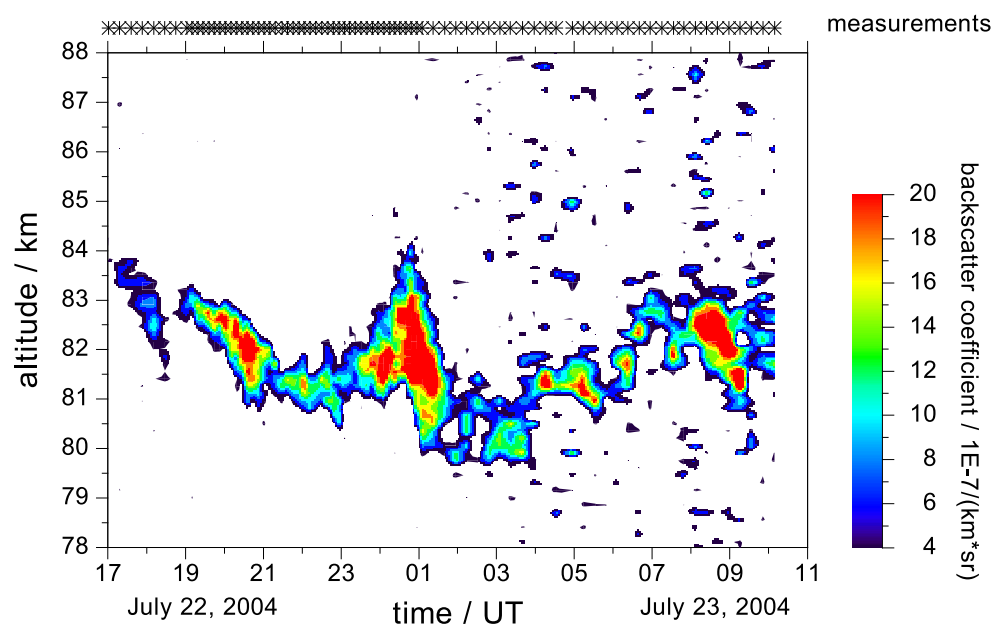

Fig. 7. Lidar observation of a noctilucent cloud on 22/23 July 2004. Shown is the development of the backscatter coefficient $\beta$ in the parallel polarisation on 532-nm wavelength.

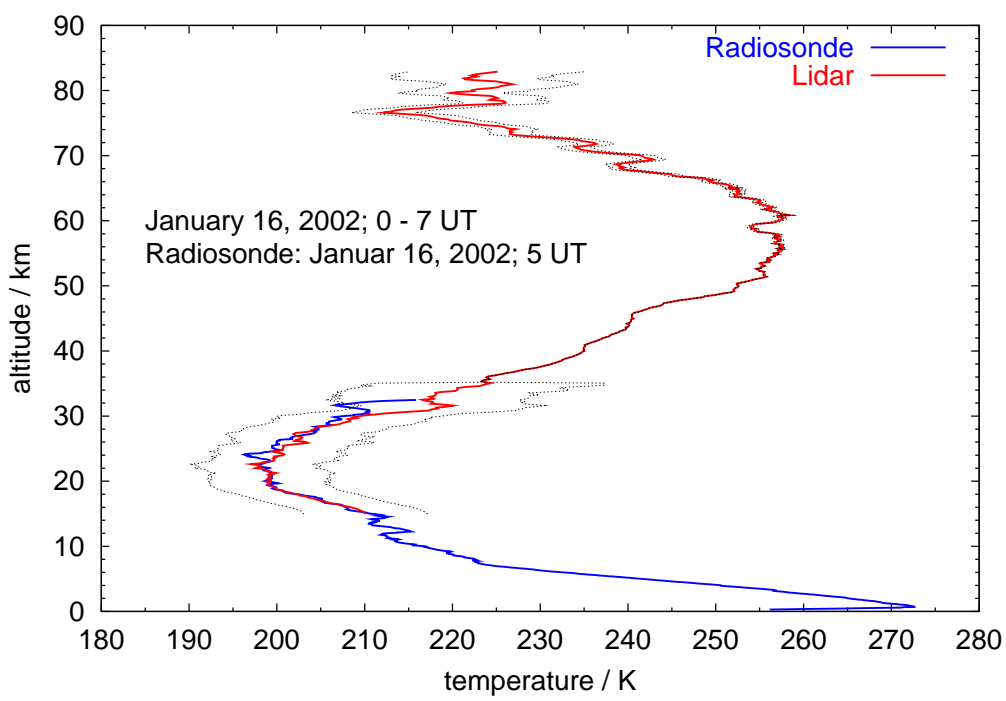

Fig. 8. Temperature profile and error measured by the U. Bonn lidar on 16 January 2002. The data cover an integration time of six hours in the time range from 0:00 UT-07:00 UT. Furthermore, a temperature profile measured by the radiosonde launched on 16 Januar 2002 at 05:00 UT at the Esrange is plotted. The increase of the temperature error at about $35 \mathrm{~km}$ altitude is due to the change in the lidar channel.

sensitive channel on 532-nm parallel polarisation is used, whereas below, data from the vibrational-Raman channel are taken. Due to the weaker signal of this channel the statistical error is much larger and thus leads to the large temperature error. The comparison with the radiosonde launched at the Esrange in the middle of the measurement time shows a nearly perfect agreement with the lidar data. The deviation of $10 \mathrm{~K}$ at $30-\mathrm{km}$ altitude can easily be caused by the geophysical variability of the atmosphere. At this altitude the radiosonde is one hundred or more kilometers away from the Esrange and shows presumably the same wave as the lidar, but with a phase shift of $180^{\circ}$.

The accuracy of the lidar temperature is predominantly determined by the seed temperature, as long as the measurement is not affected by aerosol contribution. The effect
Table 7. Accuracy and precision of a typical lidar temperature profile with 2-h integration time, taken during darkness conditions on a clear weather winter night.

\begin{tabular}{crrrr}
\hline altitude $/ \mathrm{km}$ & \multicolumn{2}{c}{ accuracy } & \multicolumn{2}{c}{ precision } \\
\hline 80 & $10 \%$ & $20 \mathrm{~K}$ & $8.2 \%$ & $16 \mathrm{~K}$ \\
65 & $1 \%$ & $2 \mathrm{~K}$ & $2.4 \%$ & $4.7 \mathrm{~K}$ \\
50 & $0.1 \%$ & $0.2 \mathrm{~K}$ & $0.7 \%$ & $1.4 \mathrm{~K}$ \\
35 & $0.01 \%$ & $0.02 \mathrm{~K}$ & $0.2 \%$ & $0.4 \mathrm{~K}$ \\
\hline
\end{tabular}

of the seed temperature decreases exponentially with altitude, assuming that an accuracy of $10 \%$ of the temperature in the seed altitude results in an accuracy of $1 \%$ in an 


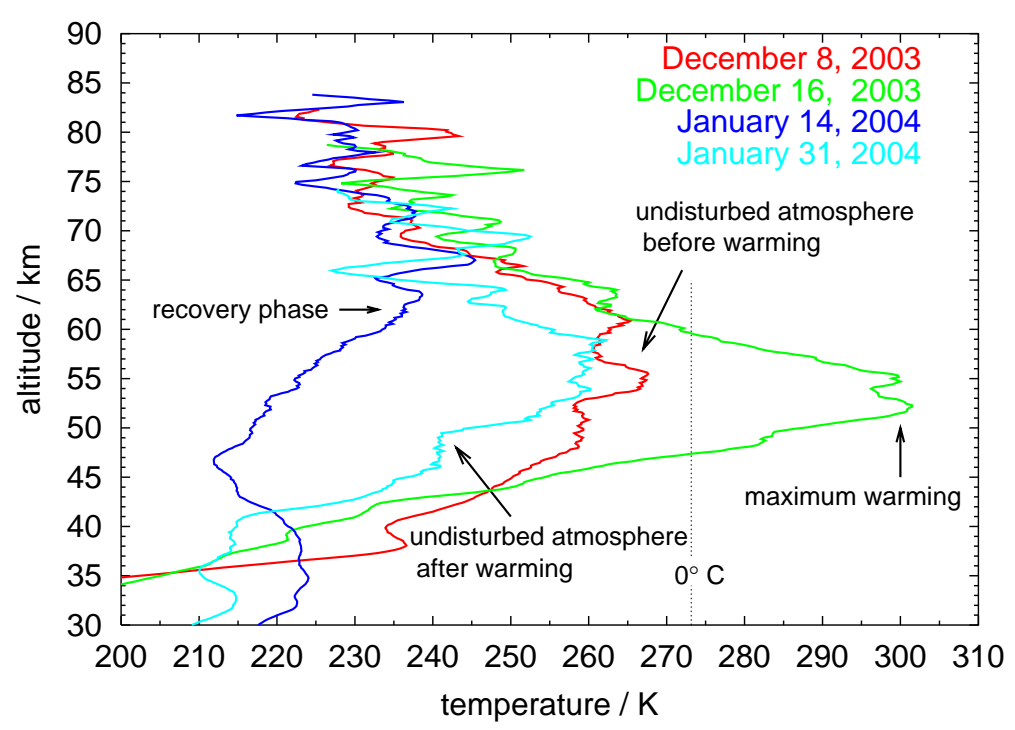

Fig. 9. Development of a stratospheric warming above the Esrange. The different stages of the warming were observed by the U. Bonn lidar during winter 2003/2004.

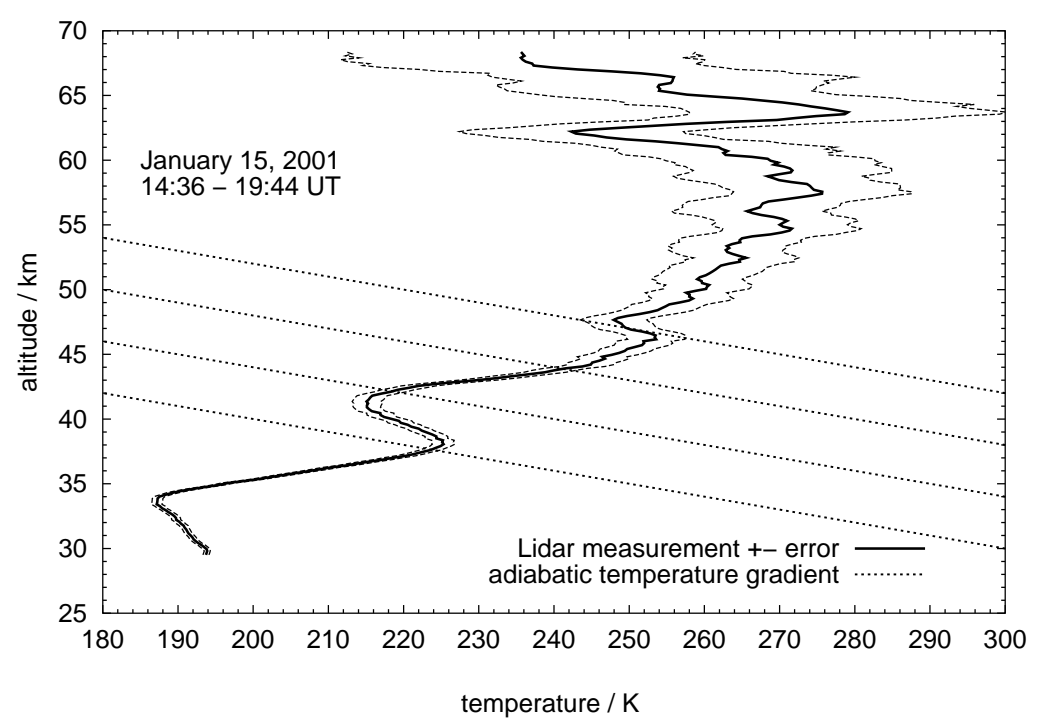

Fig. 10. Temperature profile (solid line) and error with superposed waves measured by the U. Bonn lidar on 15 January 2001 . The data cover an integration time of five hours from 14:36-19:44 UT. Additionally plotted is the adiabatic temperature gradient (dotted lines).

altitude two scale heights below the seed altitude. Besides the seed temperature the accuracy is influenced by vignetting of the low intensity edge of the Gaussian-shaped beam or by seeing-effects near the telescopes. However, these effects are varying within minutes and will be averaged out during the integration time for temperature profiles of typically more than 30 minutes and thus can be neglected. The precision of the temperature is determined by the measurement statistics and varies with altitude and integration time, as well as with the daylight and weather conditions. The starting altitude of the temperature is chosen where the statistical error falls below $10 \%$. Table 7 shows the accuracy and precision of a typical temperature profile with 2-h integration time, taken during darkness on a clear winter night.
Regular measurements during the winter measurement campaigns permit the observation of large and small-scale temperature variations above the Esrange. For example, Fig. 9 displays the different stages of a major stratospheric warming during winter 2003/2004, as described by Labitzke (1972).

Early in December the temperature profile displayed an undisturbed atmosphere (red line) with a stratopause temperature of $267 \mathrm{~K}$ at $55 \mathrm{~km}$ altitude. Eight days later, the maximum warming was observed with a stratopause temperature of $302 \mathrm{~K}$ at $52 \mathrm{~km}$ altitude (green line). About one month later, the recovery phase of the warming was detected; a nearly constant temperature profile from the middle stratosphere to the mesopause, with a variability of about $30-40 \mathrm{~K}$, occurred (dark-blue line). Again, one week 
later, the atmosphere returned to the undisturbed profile with again, a stratopause temperature of $260 \mathrm{~K}$ in $56-\mathrm{km}$ altitude (light-blue line).

Small-scale variations show up regularly as wave signatures in the temperature profiles (Fig. 10). A prominent wave signature is observable up to about $50-\mathrm{km}$ altitude during five hours of integration time. Higher up in the mesosphere the waves show smaller amplitudes and shorter wavelengths. The adiabatic temperature gradient is plotted as dotted lines. At about $48-\mathrm{km}$ altitude the measured temperature profile reaches the adiabatic temperature gradient which is an indication of an unstable atmosphere. This probably leads to wave breaking, resulting in the different wave pattern above 50-km altitude. Hence, temperature profiles can be used to analyse atmospheric gravity waves, as shown by Wilson et al. (1990), Whiteway and Carswell (1995), and Blum et al. (2004). The observation of gravity waves since 1997 revealed very clearly a strong dependency of the wave activity in the middle stratosphere on season. The difference in the potential energy density of the waves during summer and winter is about one order of magnitude $\left(\approx 10^{-1} \mathrm{~J} / \mathrm{m}^{3}\right.$ (winter) vs. $\approx 10^{-2} \mathrm{~J} / \mathrm{m}^{3}$ (summer)). This difference is due to different propagation conditions for gravity waves in summer and winter. During winter, the tropospheric, as well as the stratospheric mean flow, is directed towards the east and thus enables gravity waves to penetrate from the troposphere up to the stratosphere. During summer the tropospheric wind regime turns to westward directed winds, thus critical levels occur regularly, leading to gravity wave filtering.

\section{Summary}

The U. Bonn lidar at the Esrange is described and explained. The system is able to perform measurements on three different wavelengths and to analyse the polarisation of the backscatterd light in the visible channel at $532-\mathrm{nm}$ wavelength. In addition, these channels are daylight capable using Fabry-Perot etalons as spectral filters. This allows continuous measurements throughout the day and thus during polar summer, as well as in winter.

It is shown that the lidar data cover the troposphere, stratosphere, and mesosphere. The system is able to observe clouds and aerosols in all three altitude regimes and to measure temperature profiles from the lower stratosphere up to the mesopause. Using the calculated temperature profiles, the analysis of atmospheric gravity waves can be performed. Thus, the lidar is very well suited for research on atmospheric aerosols and dynamics at polar latitudes during all seasons.

Acknowledgements. We thank the staff of the Esrange for their always quick and uncomplicated support during the measurement campaigns. The instrument development and set up was funded by the German and European ozone research programs. We are greatly indebted to P. Scheuch, J. Schäfer, M. Langer, K. P. Müller, G. Baumgarten, and J. Siebert, who developed, constructed, built, and improved the instrument during the last 15 years. The telescope structure and several other optical mounts were built by the institute workshops; the synchronisation electronic was designed and built by the electronic workshop of the institute. We thank the competent staff from our institute workshops.

Topical Editor U.-P. Hoppe thanks a referee for his help in evaluating this paper.

\section{References}

Alpers, M., Eixmann, R., Fricke-Begemann, C., Gerding, M., and Höffner, J.: Temperature lidar measurements from 1 to $105 \mathrm{~km}$ altitude using resonance, Rayleigh, and rotational Raman scattering, Atmos. Chem. Phys., 4, 793-800, 2004,

SRef-ID: 1680-7324/acp/2004-4-793.

Arshinov, Y. F., Bobrovinkov, S. M., Zuev, V. E., and Mitev, V. M.: Atmospheric temperature measurements using a pure rotational Raman lidar, Appl. Optics, 22, 2984-2990, 1983.

Behrendt, A. and Reichardt, J.: Atmospheric temperature profiling in the presence of clouds with a pure rotational Raman lidar by use of an interference-filter-based polychromator, Appl. Optics, 39, 1372-1378, 2000.

Behrendt, A., Reichardt, J., Siebert, J., Fricke, K. H., and Weitkamp, C.: Tropospheric and stratospheric temperature measurements with lidar above Esrange in January and February 1999, Air Pollution Report 73, European Comission, ISBN 92827-5672-6, 153-156, 1999.

Beyerle, G., Neuber, R., Schrems, O., Wittrock, F., and Knudsen, B.: Multiwavelength lidar measurements of stratospheric aerosols above Spitsbergen during winter 1992/1993, Geophys. Res. Lett., 21, 57-60, 1994.

Biele, J., Tsias, A., Lou, B. P., Carslaw, K. S., Neuber, R., Beyerle, G., and Peter, T.: Nonequilibrium coexistence of solid and liquid particles in Arctic stratospheric clouds, J. Geophys. Res., 106 22 991-23 007, 2001.

Blum, U.: Lidarbeobachtungen der polaren Atmosphäre: Wolken und Wellen - Phänomene und Mechanismen, Ph.D. thesis, Universität Bonn, BONN-IR-2003-11, 2003.

Blum, U., Fricke, K. H., and Stebel, K.: Observation of clouds in the stratosphere with the U. Bonn Lidar at the Esrange, Proceedings of the 15th ESA Symposium on European Rocket and Ballon Programmes and Related Research, Biarritz May/June 2001, France, ESA-SP-471, 189-193, 2001.

Blum, U., Fricke, K. H., Baumgarten, G., and Schöch, A.: Simultaneous lidar observations of temperatures and waves in the polar middle atmosphere on the east and west side of the Scandinavian mountains: A case study on 19/20 January 2003, Atmos. Chem. Phys., 4, 809-816, 2004

\section{SRef-ID: 1680-7324/acp/2004-4-809}

Blum, U., Fricke, K. H., Müller, K. P., Siebert, J., and Baumgarten, G.: Long term lidar observations of polar stratospheric clouds at the Esrange in northern Sweden, Tellus B, 51, in press, 2005.

Browell, E. V., Butler, C. F., Ismail, S., Robinette, P. A., Carter A. F., Higdon, N. S., Toon, O. B., Schoeberl, M. R., and Tuck, A. F.: Airborne lidar observations in the wintertime Arctic stratosphere: Polar stratospheric clouds, Geophys. Res. Lett., 17, 385388, 1990.

Chen, W. N., Tsao, C. C., and Nee, J. B.: Rayleigh lidar temperature measurements in the upper troposphere and lower stratosphere, J. Atmos. Sol.-Terr. Phys., 66, 39-49, 2004.

Collis, R. T. H. and Ligda, M. G. H.: Laser radar echoes from the clear atmosphere, Nature, 203, 508, 1964. 
Crutzen, P. and Arnold, F.: Nitric acid cloud formation in the cold Antarctic stratosphere: A major cause for springtime 'ozone hole', Nature, 324, 651-655, 1986.

Dörnbrack, A., Birner, T., Fix, A., Flentje, H., Meister, A., Schmid, H., Browell, E. V., and Mahoney, M. J.: Evidence for inertia gravity waves forming polar stratospheric clouds over Scandinavia, J. Geophys. Res., 107, doi:10.1029/2001JD000452, 2002.

Fiedler, J., Baumgarten, G., and von Cossart, G.: Noctilucent clouds above ALOMAR between 1997 and 2001: Occurrence and properties, J. Geophys. Res., 108, doi:10.1029/2002JD002419, 2003.

Fiocco, G. and Grams, G.: Observations of the aerosol layer at $20 \mathrm{~km}$ by optical radar, J. Atmos. Sci., 21, 323-324, 1964.

Flueglistaler, S., Luo, B. P., Buss, S., Wernli, H., Voigt, C., Müller, M., Neuber, R., Hostetler, C. A., Poole, L. R., Flentje, H., Fahey, D. W., Northway, M. J., and Peter, T.: Large NAT particle formation by mother clouds: Analysis of SOLVE/THESEO-2000 observations, Geophys. Res. Lett., 29, doi:10.1029/2001GL014548, 2002.

Fricke, K. H. and von Zahn, U.: Mesopause temperatures derived from probing the hyperfine structure of the $\mathrm{D}_{2}$ resonance line of sodium by lidar, J. Atmos. Terr. Phys., 47, 499-512, 1984.

Fritts, D. C. and Alexander, M. J.: Gravity wave dynamics and effects in the middle atmosphere, Rev. Geophys., 41(1), 1003, doi:10.1029/2001RG000106, 2003.

Hansen, G., Serwazi, M., and von Zahn, U.: First detection of a noctilucent cloud by lidar, Geophys. Res. Lett., 16, 1445-1448, 1989.

Hansen, G., Bramstedt, K., Rozanov, V., Weber, M., and Burrows, J. P.: Validation of GOME ozone profiles by means of the ALOMAR ozone lidar, Ann. Geophys., 21, 1879-1886, 2003, SRef-ID: 1432-0576/ag/2003-21-1879.

Hedin, A. E.: Neutral atmosphere empirical model from the surface to the lower Exosphere MSISE90, J. Geophys. Res., 96, 11591172, 1991.

Jesse, O.: Auffallende Abenderscheinungen am Himmel, Meteorol. Zeitung, 2, 311-312, 1885.

Kao, C.-Y. J., Cooper, D. I., Reisner, J. M., and Eichinger, W. E.: Probing near-surface atmospheric turbulence with highresolution lidar measurements and models, J. Geophys. Res., 107, doi:10.1029/2001JD000746, 2001.

Kent, G. S. and Wright, R. W. H.: A review of laser measurements of atmospheric properties, J. Atmos. Terr. Phys., 32, 1970.

Kent, G. S., Clemesha, B. R., and Wright, R. W.: High altitude atmospheric scattering of light from a laser beam, J. Atmos. Terr. Phys., 29, 169-181, 1967.

Labitzke, K.: Temperature changes in the mesosphere and stratosphere connected with circulation changes in winter, J. Atmos. Sci., 29, 756-766, 1972.

Lübken, F.-J.: The thermal structure of the Arctic summer mesosphere, J. Geophys. Res., 104, 9135-9149, 1999.

Maimann, T. H.: Stimulated optical radiation in ruby, Nature, 187, 493-494, 1960.

McCormick, M. P., Swissler, T. J., Chu, W. P., and Fuller, W. H.: Post-volcanic stratospheric aerosol decay as measured by lidar, J. Atmos. Sci., 35, 1269-1303, 1978.
McCormick, M. P., Steel, H. M., Hamill, P., Chu, W. P., and Swissler, T. J.: Polar stratospheric cloud sightings by SAM II, J. Atmos. Sci., 39, 1387-1397, 1982.

Melfi, S. H. and Lawrence, J. D.: Observation of Raman scattering by water vapor in the atmosphere, Appl. Phys. Let., 15, 295-297, 1969.

Middleton, W. E. K. and Spilhaus, A. F.: Meteorological Instruments, University of Toronto Press, 1953.

Nicolet, M.: On the moleuclar scattering in the terrestrial atmosphere: An empirical formula for its calculation on the homosphere, Planet. Space Sci., 32, 1467-1468, 1984.

Pelon, J. and Mégie, G.: Ozone monitoring in the troposphere and lower stratosphere: Evaluation and operation of a ground-based lidar station, J. Geophys. Res., 87, 4947-4955, 1982.

Pool, L. R. and McCormick, M. P.: Airborne lidar observations of Arctic polar stratospheric clouds: Indications of two distinct growth stages, Geophys. Res. Lett., 15, 21-23, 1988.

Sassen, K.: The polarization lidar technique for cloud research: A review and current assessment, Bull. Amer. Meteorol. Soc., 72, 1848-1866, 1991.

Sassen, K. and Benson, S.: A midlatitude cirrus cloud climatology from the facility of atmospheric sensing. Part II: Microphysical properties derived from lidar depolarization, J. Atmos. Sci., 58, 2103-2112, 2001.

She, C. Y., Chen, S. S., Williams, B. P., Hu, Z. L., Krueger, D. A., and Hagan, M. E.: Tides in the mesosphere region over Fort Collins, Colorado $\left(41^{\circ} \mathrm{N}, 105^{\circ} \mathrm{W}\right)$ based on lidar temperature observations covering full diurnal cycles, J. Geophys. Res., 107, doi:10.1029/2001JD001189, 2002.

Smirnov, A., Royer, A., O’Neil, N. T., and Tarussov, A.: A study of the link between synoptic air mass type and atmospheric optical parameters, J. Geophys. Res., 99, 20 967-20 981, 1994.

Smirnov, A., O’Neil, N. T., Royer, A., Tarussov, A., and McArthur, B.: Aerosol optical depth over Canada and the link with synoptic air mass types, J. Geophys. Res., 101, 19299-19318, 1996.

Solomon, S.: Stratospheric ozone depletion: A review of concepts and history, Rev. Geophys., 37, 275-316, 1999.

Størmer, C.: Remarkable clouds at high altitudes, Nature, 123, 260261, 1929.

Thomas, G. E.: Is the polar mesosphere the miner's canary of global change?, Adv. Space Res., 18, 149-158, 1996.

Toon, O. B., Tabazadeh, A., Browell, E. V., and Jordan, J.: Analysis of lidar observations of Arctic polar stratospheric clouds during January 1989, J. Geophys. Res., 105, 20 589-20 615, 2000.

Volkert, H. and Intes, D.: Orographically forced stratospheric waves over northern Scandinavia, Geophys. Res. Lett., 19, 1205-1208, 1992.

von Zahn, U.: Are noctilucent clouds truly the "miner's canary" for global change?, EOS, 84, 261-264, 2003.

Whiteway, J. A. and Carswell, A. I.: Lidar observations of gravity wave activity in the upper stratosphere over Toronto, J. Geophys. Res., 100, 14 113-14 124, 1995.

Wilson, R., Hauchecorne, A., and Chanin, M. L.: Gravity waves in the middle atmosphere observed by Rayleigh lidar, Geophys. Res. Lett., 17, 1585-1588, 1990. 